\title{
Telomere Length Inheritance throughout Generations: Role of Germ Cell Mortality
}

\author{
Alyaa Rakha \\ Molecular Biology Department, Genetic Engineering and Biotechnology Research Institute (GEBRI), Sadat City University, \\ Sadat City, Egypt \\ Email: a.rakha82@yahoo.com
}

How to cite this paper: Rakha, A. (2021) Telomere Length Inheritance throughout Generations: Role of Germ Cell Mortality. Open Access Library Journal, 8: e7798. https://doi.org/10.4236/oalib.1107798

Received: July 28, 2021

Accepted: August 22, 2021

Published: August 25, 2021

Copyright (C) 2021 by author(s) and Open Access Library Inc.

This work is licensed under the Creative Commons Attribution International License (CC BY 4.0).

http://creativecommons.org/licenses/by/4.0/ (c) (i) Open Access

\begin{abstract}
Telomere is a structure of the repetitive DNA sequence TTAGGG and protein complex, found in vertebrates. This protein complex is known as the shelterin complex. It is localized at the end of each chromosome to protect them from deterioration or fusion with other chromosomes. Although as being part of a chromosome, the telomere is inherited from parents to their offspring, its mode of inheritance is a crucial part of the genetic transmission process. Theoretically, germ cells are thought to be immortal as they link generations, suggesting that telomere length is completely inherited. Furthermore, several studies reported that sperm telomere length gets elongated with age. This observation is consistent with other studies, which have reported that, with advancing paternal age at the time of conception, telomere length of the offspring gets increased. However, the mechanism by which telomere becomes longer is not fully understood. Moreover, it has been reported that there is a negative correlation between maternal age at conception and the offspring's telomere length; whereas other studies reported that there is no correlation between those data. Herein, we review our current understanding of these topics and compare different aspects of the telomere length behavior in germ cells, germ cells mortality and, in accordance, the risks of aging on reproduction.
\end{abstract}

\section{Subject Areas}

Cell Biology

\section{Keywords}

Telomere, Telomerase, Germ Cell, Inheritance, Mortality

\section{Introduction}

Telomere is a noncoding region of repetitive DNA sequence (TTAGGG), which 
locates at the end of each chromosome to protect it from deterioration or fusion with other chromosomes and then prevent cellular senescence and apoptosis (programmed cell death). Each time cells divide, telomeres show continuous shrinkage in length as a result of incomplete DNA replication [1]. As Telomere Length (TL) declines throughout life, this magnitude is proposed to act as a biomarker of aging [2]. This continuous decrease in TL is replenished by an enzyme called telomerase, which is expressed at high levels in some types of cells such as germ cells [3].

Dolly cloning has shed light on the importance of telomere length inheritance. Since Dolly was born by Somatic Cell Nuclear Transfer (SCNT), not by natural mating, it has shown premature senescence due to the inheritance of short TL [4]. This indicated that natural mating may have a unique mechanism to preserve TL throughout generations and hence, the immortality of germ cells has been estimated [5].

As germ cells link generations, one might speculate that telomere is fully transmitted from a generation to another. However, TL study faces many challenges as there are many factors influencing TL, which limit our comprehensive knowledge in this aspect. These factors are not only limited to the age factor, but also to the environmental factors [6] such as smoking, high levels of stress, obesity [7] [8] [9] and oxidative stress [10] [11]. The diversity among these factors might explain the considerable TL variations between aged monozygotic twins [12].

Telomere length and telomerase activity in germ cells were studied by different laboratories. Starting from germ cell division, it has been reported that spermatogenesis (the process of producing the mature spermatozoa from male germ cells) is associated with TL elongation [13]. Also, Sperm Telomere Length (STL) gets longer with aging and accordingly it shows an increase in STL in older men compared to younger [14] [15]. In consistent with these findings, several reports analyzed the effect of Paternal Age at Conception (PAC) on TL of the offspring and demonstrated a positive effect, indicating the effect of increased STL on offspring from older fathers [14] [16]-[21]. These studies measured TL from leukocytes in the offspring as Okuda et al. and Kimura et al. demonstrated that leukocyte's TL is best of reflecting TL of any other cell types [22] [23].

Maternal age effect on Oocyte Telomere Length (OTL) and TL of the offspring is not well understood. A negative correlation between the effect of Maternal Age at Conception (MAC) and TL of the offspring has been proposed based on the fact that increasing woman age leads to genetic disorders to the embryo, which may reflect short TL inherited from the maternal side, reviewed in [24]. On the other hand, some studies reported no significant relation between MAC and TL of the offspring [14] [16] [18]. Furthermore, a positive correlation between them has been demonstrated [16] [19]. However, the authors suggested that this correlation may be caused by the paternal effect, not the maternal [19].

In this review, we summarize the current information and compare different results, obtained from previous studies seeking for understanding the mechan- 
ism by which TL is inherited from parents to their offspring and its effect on their TL and health. We are also aiming to identify the character of germ cells mortality and, in accordance, the TL of the coming generations.

\section{Paternal Age Effect on TL of the Offspring}

It has been demonstrated that telomeres get lengthened with age in human sperm [14] [15]. Aston et al. have reported that STL increases by average of $57 \mathrm{bp} /$ year, which support a positive correlation between male age and STL [15]. Thus, it is not surprising to find that the more PAC advances, the more TL of offspring increases [14] [16] [17] [19] [20] [21] [25]. Several investigators demonstrated that TL of the offspring gets longer by average of $20 \mathrm{bp} /$ year due to the PAC effect [14] [16] [17] [26]. That is, each year PAC advances, there may be an opportunity to have a child whose $20 \mathrm{bp}$-longer telomeres. This positive correlation between PAC and TL of the offspring gives a strong possible explanation for TL variation among individuals [16], in addition to the environmental factors.

To the best of our knowledge, no defined mechanism has been provided to illustrate how STL increases with age and its role in the positive correlation between PAC and the offspring TL. However, a number of hypotheses were given to illustrate this PAC-TL association, including: 1) The selectivity of germ line stem cell [14] [21]; 2) A phenomenon known as Selfish Spermatogonial Selection (SSS) [27]; 3) The presence of high levels of testicular telomerase [16] [21]; and 4) Epigenetics [14] [21]. Below, we discuss these four categories in order to shed the light on these proposed hypotheses.

\subsection{Germ Line Stem Cell Selectivity}

Germ line stem cells (GSCs) are unipotent stem cells, found in both male and female genital system. These cells proliferate mitotically to give daughter stem cells (self-renewing) and also they undergo meiosis and differentiate into haploid gametes, which are sperms in male and oocytes in female [28]. These cells confer high telomerase activity [29]. Kimura et al. and Hjelmborg et al. suggested that elongation of STL by aging may be related to GSCs as they start to produce the aging-resistant sperms [14] [21]. The subset of GSCs with long telomeres confers a favorable survival advantage [14] [30].

Furthermore, Hjelmborg et al. evaluated how similar the TL of dizygotic twins compared with the TL of monozygotic twins of old fathers and they found that the dizygotic twins had shown more similarity in their TL [21]. This supports the mechanism of GSC selectivity where the two different sperms that fertilized the two eggs may have arisen from the same stem cell and thereby show resemblance in TL as it has been thought that the high STL variance in old men is not transmitted to the offspring. Instead, there is a selective bias by which only a subset of sperms with low variance is able to fertilize the oocyte to produce offspring with low TL variance [27].

At any rate, the survival of a subset of GSC, if the only parameter, would cause 
a sudden increase in TL of old fathers. However, the result obtained by different studies imply that it is a linear increase of offspring's TL with advancing PAC, starting from young to old ages [14] [16] [17] [19] [20] [21] [25]. Therefore, this mechanism of paternal TL inheritance does not match with the previously obtained result. Thus, further studies are required to illustrate this conflict.

\subsection{Selfish Spermatogonial Selection}

Selfish Spermatogonial Selection (SSS) is a phenomenon that takes place in human testis wherein some of the spermatogonial stem cells acquire a mutation that enhances their proliferation capacity [31] [32]. This mutation is thought to regulate both mitotic and meiotic division, i.e., self-renewal and differentiation of spermatogonial stem cells [32]. Therefore, the SSS phenomenon is thought to give a possible explanation for STL increase in prevalence with PAC [27]. According to Eisenberg and Kuzawa, the acquired mutation matches the STL distribution with advancing male ages, whereas selectivity allows only a subset of spermatogonial stem cells to differentiate into sperms with the long TL. Meanwhile, sperms with shorter telomeres continue to produce and contribute to a variance in STL with age. Moreover, the higher proliferation rate of the mutated cells may contribute to STL increase through enhancing the activity of telomerase resulting in a consistent positive correlation between male age and STL [27].

Although SSS hypothesis can explain the PAC-TL relation in the case of old men, it cannot explain how young men can have longer STL with age because the mutated sperms leads to give birth of a child with paternal age-effect diseases [33] [34] and according to Arnheim and Calabrese, young men (19 - 23 years old) show low frequency of this kind of mutations [35]. So, this hypothesis may not be able to explain the positive dependency of the offspring's TL on their PAC as this range of ages follows the positive correlation between PAC and STL and the offspring TL [14] [16] [17]. Further research need to resolve this conflict.

\subsection{Telomerase Activity}

Telomerase is a reverse transcriptase that retains telomere length each time cells divide. It is highly active in certain types of cells such as stem cells [36], embryonic cells [13] [37], cancer cells [38] and germ cells [37]. The RNA component of telomerase had shown high expression in human spermatogonia and primary and secondary spermatocyte [39]. Spermatogonia are diploid cells that lie on the basal lamina of the convoluted seminiferous tubules and proliferate into diploid primary spermatocytes, which in turns differentiate by meiosis into haploid secondary spermatocytes. Secondary spermatocytes differentiate into spermatids, which eventually give rise to the mature spermatozoa. This process is known as "spermatogenesis".

High expression of telomerase RNA component in primary and secondary spermatocyte indicates that it may have an influence on TL elongation upon aging, reviewed in [27]. However, high telomerase activity in some stem cell types, 
such as skin, intestine and white blood cells, is insufficient even to maintain TL in these cells [37]. For instance, Aston et al. reported that hematopoietic stem cell exhibit a decrease in TL by 19 bp/year [15], despite the high activity of telomerase in these cells. On the other hand, its activity in germ cells has the ability to increase TL during the process of spermatogenesis; specifically, during the process of spermatocytes formation with a noticeable decreases in spermatids TL [13] [40]. Jorgensen et al. pointed out that such decline is observed at a similar or slightly higher rate in old men [40], also, telomerase activity has not been found in the germ cells of elderly individuals [41], suggesting that STL elongation with age might be due to germ line stem cell selectivity not telomerase activity in germ cells, reviewed in [27]. However, Achi et al. demonstrated that TL gets elongated again in the mature spermatozoa [13]. The amount of TL elongation by each replicative cycle had been estimated to be $2.48 \mathrm{bp}$ [15].

Meanwhile, this proposed hypothesis may encounter various impediments. For instance, the telomerase activity is incompatible with the increase in STL variance associated with age [14] because telomerase activity would increase TL in all sperms, not only in a subset. However, it is possible that the group with shortened TL may have not undergone many replications like the other ones, which may cause their telomeres to be shorter. Moreover, telomerase activity in primary and secondary spermatocytes cannot explain the continues elongation of STL with age since these cells only differentiate to give spermatozoa and do not undergo self-renewal without which, they cannot increase TL in the following subset of spermatozoa. So, if the factor is testicular telomerase activity, then it may be in a cell that takes place in the process of spermatogenesis and, at the same time, undergo self-renewal. This is the germ line stem cell, also called type A spermatogonia. These cells divide mitotically by self-renewal and they also proliferate to generate type B spermatogonia, which differentiate in the process of spermatogenesis into sperms. However, it is still unclear if GSC self-renewal is associated with TL elongation in the daughter cells or not, yet.

\subsection{Epigenetics}

Epigenetics is the study of alteration in gene expression without any change in DNA sequence. histone modification, DNA methylation and non-coding RNA are examples of epigenetics [42]. In this regards, Kimura et al. and Hjelmborg et al. suggested an epigenetic remodeling of GSCs that influences the telomere lengthening in sperms of older men [14] [21]. Also, Baird et al. speculated that sperm telomere elongation might be back to imprinting [43], which is a mechanism of chromatin remodeling that takes place in gametes and transmitted to the embryo [44].

\section{Maternal Age Effect on TL of the Offspring}

Several studies have provided a clear-cut evidence for the positive correlation between PAC and TL of the offspring. On the contrary, very limited number of 
studies has reported the effect of Maternal Age at Conception (MAC) on the offspring's TL [14] [18] [19]. Owing to the limited number of oocytes an individual female is born with, it is plausible to think that Oocyte Telomere Length (OTL) might be quite stable with age [14]. However, studying human oocytes is hindered by numerous obstacles; including, at least in part, the difficulty in obtaining ethical consents for utilizing oocytes in research. Moreover, the technical challenges associated with DNA extraction from singular oocytes limit the obtained yield and subsequent applications. Alternatively, recent studies demonstrated the relation between MAC and TL in the offspring of other species such as songbird [45] and cows [46]. However, such studies cannot be conclusive in term of Homo sapiens species because the biology of telomere varies markedly among species [37] [47].

Nevertheless, Keefe and colleagues proposed a negative effect of MAC on the offspring TL [24]. In this theory, telomeres are thought to play a vital role in meiotic division of germ cells as they tether chromosomes to facilitate their alignment, pairing, synapsis and chiasmata formation during early meiosis, reviewed in [24]. Thus, short telomeres may lead to a mutated oocyte causing further congenital disorders upon fertilization. Moreover, in proper clinical settings, in vitro fertilization is known to be less efficient in women with shorter telomeres [24]. Also, it is proposed that telomeres get shorter in aging females [27] [48]; providing possible clues on congenital abnormalities observed in infants conceived from elder women. For instance, Reizel et al. suggested that oocytes ovulated at old ages have undergone more replicative cycles during fetal development than those ovulated at young ages [49]. Although the latter suggestion is consistent with Keefe et al. theory, empirical evidence remains elusive.

Reizel et al. suggest a small difference in the number of replication cycles between early-ovulated and late-ovulated oocytes. So, the observed maternal age effect may arise, instead, due to the de novo mutations acquired in oocytes post fertilization [50]. Also, a number of studies demonstrated that there is no significant correlation between MAC and TL of the offspring [14] [16] [18].

On the other hand, Unryn et al. found that the correlation tends to be slight positive [16]. Also Ferlin et al. found that TL of the offspring increases with advancing maternal age [19]. However, the authors suggested that, according to previously published data, this relation might be influenced by the paternal age effect not the maternal, since there is usually a high correlation between their ages. So far, to the best of our knowledge, the available literature provides contracting evidence in describing the effect of maternal age and OTL and studies are still required to clearly resolve this issue.

\section{Mortality of Germ Cells}

Cell mortality is defined as the cellular inability to undergo any of the vital processes leading to programmed cellular death. The cell mortality takes place when telomeres of a destined cell get too short; following a number of replicative cycles where chromosomes reach a critical length at which they can't replicate 
anymore. This, in turn, triggers the programmed cell death, a process also known as apoptosis as shown in Figure 1.

Although telomeres are in a continuous shrinkage each time cells divides, telomerase usually compensates this loss by adding the telomeric sequence (TTAGGG) at the end of chromosomes. The immortality depends mainly on the activity of the telomerase in each distinct cell type [51]. If telomerase is sufficient to either maintain or increase TL with each cell division, the dividing cells are immortal; such as cancer cells [38] (Figure 1). However, insufficient telomerase activity leads to cell mortality as seen in hematopoietic stem cells, which show a decrease in TL by 19 bp/year [15].

No study, yet has demonstrated if germ cells express telomerase in sufficient levels to be immortal or not. The immortality of germ cells is still a theory that depends on the fact that these cells link generations [5]. The positive correlation between male age and STL is not a sufficient evidence for germ cell immortality because the factor causing this phenomenon is still unknown. Further detailed studies are required to provide the absolute evidence for the character of mortality or immortality of male and female germ cell.

\section{TL of Future Generations}

Irrespective of the mechanisms, telomere lengthening in sperms and offspring with advancing the father's age is a fact. This may give a clear-cut evidence that telomere is getting longer across generations. Furthermore, one is not in need to have a child in an old age to achieve this elongation throughout generations because spermatogenesis causes a slight telomere elongation in spermatozoa (2.48 bp in each replicative cycle), regardless the age of conception [15] (Figure 1). Also, young ages were included in the positive PAC-TL correlation (starting from 15 years old) [16]. However, in such young paternal ages, the increase in TL of the offspring would be very small, according to the PAC-TL correlation. Introducing that, late paternity can cause more progressive elongation in TL of the successive generations than early paternity can [15].

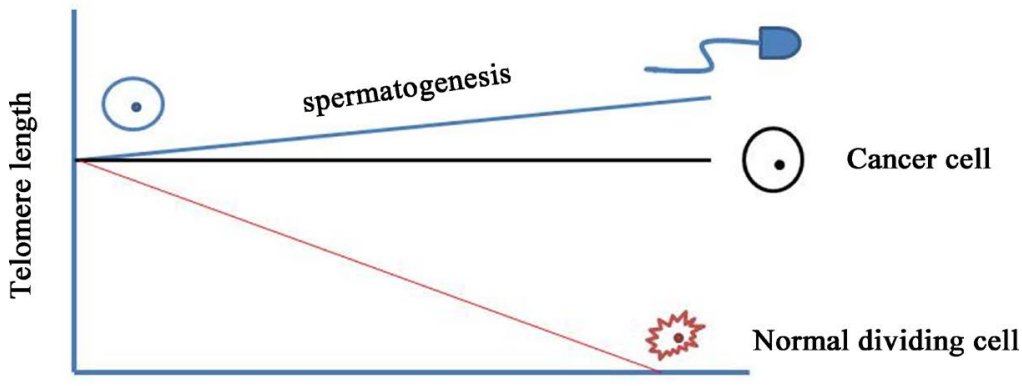

Cell division

Figure 1. Telomere length of germ cells, cancer cells and normal dividing cells in relation to cell division. Spermatogenesis causes increase in TL, whereas cancer cells show stability in TL with cell division. Normal dividing cells undergo apoptosis after several replicates due to the decrease in their TL. 
How about the MAC effect? Although MAC-TL correlation is not fully understood yet, many studies have suggested that the inherited long telomeres from the paternal side can compensate the TL inherited from the mother [18] [52] [53]. Meaning that MAC effect on the offspring TL may be disregarded in this context and consider only the PAC effect, which positively affect the TL of successive generations.

Conversely, Eisenberg and Kuzawa thought that TL do not increase across generations, suggesting that in the few years between puberty and well-developed sperm production, many cell divisions take place, which may cause TL shortening [27]. This shortening is thought to encounter the positive PAC effect on the TL of the offspring [27]. However, further studies are still required to confirm this hypothesis and obtain the net effect on the successive generations.

\section{The Appropriate Age for Reproduction}

Several studies demonstrated the importance of having long telomeres in our cells. Among several aspects, cells with longer TL exhibit an enhanced cell proliferation, better immune response with higher resistance to infections [18] and efficient wound healing [54]. Adding to that, Haycock et al. and Aviv et al. reported that long TL increases the maintenance of blood vessels and reduces the formation of senescent cells in the atherosclerotic plaques [55] [56].

Considering the PAC effect on the TL of the offspring, one might speculate that conception at older ages is better in order to have children with long telomeres. However, increased paternal age is reported to have risk on the health of the offspring and it is well established that increasing MAC could be very harmful to the embryo. As reviewed in [24], increasing MAC contributes to infertility, apportions and increases the risk of having defected children. This is due to the meiotic dysfunction during the oocyte formation, which increases with advancing woman age. Several studies reported that women over 35 years old show higher risk of having such age defects than the younger [57]. Additionally, advancing paternal age has harmful effects on the offspring, including the risk of miscarriage, having a handicapped child and other diseases such as schizophrenia and autism [57]. These risks increase with paternal age as a result of defects in several factors such as reproductive hormones, chromosomal structure of sperm, de novo mutations and other factors, reviewed in [57]. Stone et al. reported that sperm quality and quantity begin to deteriorate at the age of 35 , which is consistent with the age threshold of women for reproduction [58].

This risk of old parents implies that conception at old ages ( $>35$ years old) is not favored for both father and mother. On the other hand, to give birth earlier may not be of such benefit for the offspring. In the regard of the PAC-TL association, conception at young ages may lead to the reproduction of offspring with shorter TL than those born to old parents which may not be beneficial. Several studies reported that individuals with short TL show a number of age-related diseases such as dementia, atherosclerosis, insulin resistance, hypertension, myocar- 
dial infarction and stroke, reviewed in [14]. Also, it has been demonstrated that elderly individuals with shortened TL have less opportunity for survival [59] [60]. The potential cause of the harmful effects driven by the shortened TL is likely that cell division requires a critical length of telomeres and the shortened TL is supposed to drive cells to senescence [61], which, in turn, causes multiple age-related diseases and reduces survival opportunity. Further, TL has shown to be shorter in women who go through menopause, the time at which the woman menstrual cycles permanently cease as a result of aging, earlier than others [62] [63] [64].

Several studies reported varying results regarding the nature of relationship between TL and cancer. Aviv et al. suggested that individuals with long TL may be predisposed to a higher risk of cancer, since long-telomeric cells provide an advantageous proliferation of oncogenic mutations that drive and promote cancerous neoplasia [56]. Furthermore, another study demonstrated that genetically increased TL is associated with several cancers such as bladder cancer, glioma and lung adenocarcinoma [65]. On the contraty, long TL may also exhibit tumor suppression properties since long telomeres are supposed to enhance the immune function [27]. In a similar line, Ma et al. and Zhu et al. have reported that long TL is associated with decreased risk of cancers or even has no any association with cancer development [66] [67]. Also, short TL may induce cancer development as a result of genomic instability [56]. This variation in results is thought to be due to the presence of other environmental and personal factors such as smoking that can contribute to telomere shortening and increase cancer risk at the same time [68]. Also, Haycock et al. supposed that these contrasting results imply the difficulty of designing such studies, in addition to possible measurement errors [65]. Therefore, further studies are deeply required in order to resolve these contradictions.

As a result of the mentioned risks of old parental ages, the risk of inheriting short telomeres for the offspring and the supposed risk of very high and very short TL on cancer development, it may be better to avoid very young and old ages for reproduction. Further studies are needed to determine the best age for conception in order to increase the opportunity of having more healthy offspring and reduce the phenomenon of handicapped children.

\section{Conclusions}

It has become an established fact that STL gets longer as man ages and consequently, the offspring of older fathers show a higher increase in TL compared to younger counterparts. According to the available literature, there are many possible explanations of this phenomenon, none of which have emphasized the immortality of germ cell. More studies are required to clarify the character of male and female germ cell mortality or immortality. MAC effect on the TL of the offspring is not well understood.

Regardless the character of immortality, there is an evidence for TL increase during spermatogenesis and also an elongation of TL in the offspring with ad- 
vancing man age. In addition, the long telomeres inherited from the father are thought to compensate the short TL inherited from the maternal side, suggesting that TL may be getting longer throughout generations. However, further studies are still required to confirm this hypothesis.

The positive relation between PAC and TL of the offspring suggests that having birth at advanced ages may be useful for the health of the offspring, but offspring of old parents are highly exposed to suffer from genetic diseases. Therefore, more studies are still required to specify a definite appropriate age for conception.

\section{Acknowledgements}

I would like to thank Mohamad Moustafa Ali (Department of Medical Biochemistry and Cell Biology, Sahlgrenska Academy, Sweden) for the valuable discussion, proof reading and help in preparing the manuscript.

\section{Conflicts of Interest}

The author declares no conflicts of interest.

\section{References}

[1] Lindsey, J., McGill, N.I., Linsey, L.A., Green, D.K. and Cooke H.J. (1991) In Vivo Loss of Telomeric Repeats with Age in Humans. Mutation Research/DNAging, 256, 45-48. https://doi.org/10.1016/0921-8734(91)90032-7

[2] Mather, K.A., Jorm, A.F., Parslow, R.A. and Christensen, H. (2010) Is Telomere Length a Biomarker of Aging? A Review. The Journals of Gerontology: Series A, 66A, 202-213.

[3] Wright, W.E., Piatyszek, M.A., Rainey, W.E., Byrd, W. and Shay, J.W. (1996) Telomerase Activity in Human Germline and Embryonic Tissues and Cells. Developmental Genetics, 18, 173-179. https://doi.org/10.1002/(SICI)1520-6408(1996)18:2\%3C173::AID-DVG10\%3E3.0.C $\underline{\mathrm{O} ; 2-3}$

[4] Rakha, A. (2015) Cloning Efficiency and a Comparison between Donor Cell Types. Cloning and Transgenesis, 4, Article No. 141. https://doi.org/10.4172/2168-9849.1000141

[5] McLaren, A. (2001) Mammalian Germ Cells: Birth, Sex, and Immortality. Cell Structure and Function, 26, 119-122. https://doi.org/10.1247/csf.26.119

[6] Huda, N., Tanaka, H., Herbert, B.S., Reed, T. and Gilley, D. (2007) Shared Environmental Factors Associated with Telomere Length Maintenance in Elderly Male Twins. Aging Cell, 6, 709-713. https://doi.org/10.1111/j.1474-9726.2007.00330.x

[7] Epel, E.S., Blackburn, E.H., Lin, J., Dhabhar, F.S., Adler, N.E., Morrow, J.D. and Cawthon, R.M. (2004) Accelerated Telomere Shortening in Response to Life Stress. Proceedings of the National Academy of Sciences of the United States of America, 101, 17312-17315. https://doi.org/10.1073/pnas.0407162101

[8] Valdes, A.M., Andrew, T., Gardner, J.P., Kimura, M., Oelsner, E., Cherkas, L.F., Aviv, A. and Spector, T.D. (2005) Obesity, Cigarette Smoking, and Telomere Length in Women. Lancet, 366, 662-664. https://doi.org/10.1016/S0140-6736(05)66630-5

[9] Cherkas, L.F., Aviv, A., Valdes, A.M., Hunkin, J.L., Gardner, J.P., Surdulescu, G.L., Ki- 
mura, M. and Spector, T.D. (2006) The Effects of Social Status on Biological Aging as Measured by White-Blood-Cell Telomere Length. Aging Cell, 5, 361-365. https://doi.org/10.1111/j.1474-9726.2006.00222.x

[10] Cattan, V., Mercier, N., Gardner, J.P., Regnault, V., Labat, C., Mäki-Jouppila, J., Nzietchueng, R., Benetos, A., Kimura, M., Aviv, A. and Lacolley, P. (2008) Chronic Oxidative Stress Induces a Tissue-Specific Reduction in Telomere Length in CAST/Ei Mice. Free Radical Biology \& Medicine, 44, 1592-1598. https://doi.org/10.1016/j.freeradbiomed.2008.01.007

[11] Shlush, L.I., Skoreckia, K.L., Itzkovitzc, S., Yehezkela, S., Segeva, Y., Shacharb, H., Berkovitzb, R., Adirb, Y., Vultod, I., Lansdorpd, P.M. and Seliga, S. (2011) Telomere Elongation Followed by Telomere Length Reduction, in Leukocytes from Divers Exposed to Intense Oxidative Stress-Implications for Tissue and Organismal Aging. Mechanisms of Ageing and Development, 132, 123-130. https://doi.org/10.1016/j.mad.2011.01.005

[12] Kadota, K., Hayakawa, K., Doi, S., Kanamori, M. and Cai, Y. (2007) Factors Affecting the Intrapair Differences of Telomere Length in Aged Identical Twins. Twin Research and Human Genetics, 10, Article No. 36.

[13] Achi, M.V., Ravindranath, N. and Dym, M. (2000) Telomere Length in Male Germ Cells Is Inversely Correlated with Telomerase Activity. Biology of Reproduction, 63, 591-598. https://doi.org/10.1095/biolreprod63.2.591

[14] Kimura, M., Cherkas, L.F., Kato, B.S., Demissie, S., Hjelmborg, J.B., Brimacombe, M., Cupples, A., Hunkin, J.L., Gardner, J.P., Lu, X., Sastrasinh, M., Province, M.A. and Aviv, A. (2008) Offspring's Leukocyte Telomere Length, Paternal Age, and Telomere elongation in Sperm. PLoS Genetics, 4, Article No. e37. https://doi.org/10.1371/journal.pgen.0040037

[15] Aston, K.I., Hunt, S.C., Susser, E., Kimura, M., Factor-Litvak, P., Carrell, D. and Aviv, A. (2012) Divergence of Sperm and Leukocyte Age-Dependent Telomere Dynamics: Implications for Male-Driven Evolution of Telomere Length in Humans. Molecular Human Reproduction, 18, 517-522. https://doi.org/10.1093/molehr/gas028

[16] Unryn, B.M., Cook, L.S. and Riabowol, K.T. (2005) Paternal Age Is Positively Linked to Telomere Length of Children. Aging Cell, 4, 97-101. https://doi.org/10.1111/j.1474-9728.2005.00144.x

[17] De Meyer, T., Rietzschel, E.R., Buyzere, M.L.D., Bacquer, D.D., Criekinge, W.V., Backer, G.G.D., Gillebert, T.C., Oostveldt, P.V. and Bekaert, S. (2007) Paternal Age at Birth Is an Important Determinant of Offspring Telomere Length. Human Molecular Geneics, 16, 3097-3102. https://doi.org/10.1093/hmg/ddm271

[18] Eisenberg, D.T.A., Borja, J.B., Hayes, M.G. and Kuzawa, C.W. (2017) Early Life Infection, but Not Breastfeeding, Predicts Adult Blood Telomere Lengths in the Philippines. American Journal of Human Biology, 29, e22962. https://doi.org/10.1002/ajhb.22962

[19] Ferlin, A., Rampazzo, E., Rocca, M.S., Keppel, S., Frigo, A.S., Rossi, A.D. and Foresta, C. (2013) In Young Men Sperm Telomere Length Is Related to Sperm Number and Parental Age. Human Reproduction, 28, 3370-3376. https://doi.org/10.1093/humrep/det392

[20] Broer, L., Codd, V., Nyholt, D.R., Deelen, J., Mangino, M., Willemsen, G., Albrecht, E., Amin, N., Beekman, M., Geus, E.J.D Henders, A., Nelson, C.P., Steves, C.J., Wright, M.J., de Craen, A.J.M., Isaacs, A., Matthews, M., Moayyeri, A., Montgomery, G.W., Oostra, B.A., Vink, J.M., Spector, T.D., Slagboom, P.E., Martin, N.G., Samani, N.J., van Duijn, C.M. and Boomsma, D.I. (2013) Meta-Analysis of Telomere Length in 19,713 Subjects Reveals High Heritability, Stronger Maternal Inheritance and a Paternal Age Effect. European Journal of Human Genetics, 21, 1163-1168. 
https://doi.org/10.1038/ejhg.2012.303

[21] Hjelmborg, A.B., Dalga, C., Mangino, M., Spector, T.D., Halekoh, U., Moller, S., Kimura, M., Horvath, K., Kark, J.D., Christensen, K., Kyvik, K.O. and Aviv, A. (2015) Paternal Age and Telomere Length in Twins: The Germ Stem Cell Selection Paradigm. Aging Cell, 14, 701-703. https://doi.org/10.1111/acel.12334

[22] Okuda, K., Bardeguez, A., Gardner, J.P., Rodriguez, P., Ganesh, V., Kimura, M., Skurnick, J., Awad, G. and Aviv, A. (2002) Telomere Length in the Newborn. Pediatric Pulmonology, 52, 377-381. https://doi.org/10.1203/00006450-200209000-00012

[23] Kimura, M., Gazitt, Y., Cao, X.J., Zhao, X.Y., Lansdorp, P.M. and Aviv, A. (2010) Synchrony of Telomere Length among Hematopoietic Cells. Experimental Hematology, 38, 854-859. https://doi.org/10.1016/j.exphem.2010.06.010

[24] Keefe, D.L., Liu, L. and Marquard, K. (2007) Telomeres and Meiosis in Health and Disease: Telomeres and Aging-Related Meiotic Dysfunction in Women. Cellular and Molecular Life Sciences, 64, 139-143. https://doi.org/10.1007/s00018-006-6466-Z

[25] Eisenberg, D.T.A. and Kuzawa, C.W. (2018) The Paternal Age at Conception Effect on Offspring Telomere Length: Mechanistic, Comparative and Adaptive Perspectives. Philosophical Transactions of the Royal Society B, 373, Article ID: 20160442. https://doi.org/10.1098/rstb.2016.0442

[26] Arbeev, K.G., Hunt, S.C., Kimura, M., Aviv, A. and Yashin, A.I. (2011) Leukocyte Telomere Length, Breast Cancer Risk in the Offspring: The Relations with Father's Age at Birth. Mechanisms of Ageing and Development, 132, 149-153. https://doi.org/10.1016/j.mad.2011.02.004

[27] Eisenberg, D.T.A., Hayesa, M.G. and Kuzawaa, C.W. (2012) Delayed Paternal Age of Reproduction in Humans Is Associated with Longer Telomeres across Two Generations of Descendants. Proceedings of the National Academy of Sciences of the United States of America, 109, 10251-10256. https://doi.org/10.1073/pnas.1202092109

[28] Crittenden, S.L., Troemel, E.R., Evans, T.C. and Kimble, J. (1994) GLP-1 Is Localized to the Mitotic Region of the C. elegans Germ Line. Development, 120, 2901-2911. https://doi.org/10.1242/dev.120.10.2901

[29] Pech, M.F., Garbuzov, A., Hasegawa, K., Sukhwani, M., Zhang, R.J., Benayoun, B.A., Brockman, S.A., Lin, S., Brunet, A., Orwig, K.E. and Artandi, S.E. (2015) High Telomerase Is a Hallmark of Undifferentiated Spermatogonia and Is Required for Maintenance of Male Germline Stem Cells. Genes \& Development, 29, 2420-2434. https://doi.org/10.1101/gad.271783.115

[30] Antunes, D. F., Kalmbach, K., Wang, F., Dracxler, R., Seth-Smith, M., Kramer, Y., Buldo-Licciardi, J., Kohlrausch, F. and Keefe, D. (2015) A Single-Cell Assay for Telomere DNA Content Shows Increasing Telomere Length Heterogeneity, as Well as Increasing Mean Telomere Length in Human Spermatozoa with Advancing Age. Journal of Assisted Reproduction and Genetics, 32, 1685-1690.

https://doi.org/10.1007/s10815-015-0574-3

[31] Goriely, A., McGrath, J.J., Wilkie, A.O.M. and Malaspina, D. (2013) "Selfish Spermatogonial Selection": A Novel Mechanism for the Association between Advanced Paternal Age and Neurodevelopmental Disorders. American Journal of Psychiatry, 170, 599-608. https://doi.org/10.1176/appi.ajp.2013.12101352

[32] Maher, G.J., Goriely, A. and Wilkie, A.O. (2013) Cellular Evidence for Selfish Spermatogonial Selection in Aged Human Testes. Andrology, 2, 304-314. https://doi.org/10.1111/j.2047-2927.2013.00175.x

[33] Ralph, H.K. (2018) Evaluating Selfish Spermatogonial Selection and Its Role in Human Disease. Ph.D. Dissertation, University of Oxford, Oxford. 
[34] Goriely, A. and Wilkie, A.O.M. (2012) Paternal Age Effect Mutations and Selfish Spermatogonial Selection: Causes and Consequences for Human Disease. American Journal of Human Genetics, 90, 175-200. https://doi.org/10.1016/j.ajhg.2011.12.017

[35] Arnheim, N. and Calabrese, P. (2016) Germline Stem Cell Competition, Mutation Hot Spots, Genetic Disorders, and Older Fathers. Annual Review of Genomics and Human Genetics, 17, 219-243. https://doi.org/10.1146/annurev-genom-083115-022656

[36] Flores, I., Canela, A., Vera, E., Tejera, A., Cotsarelis, G. and Blasco, M.A. (2008) The Longest Telomeres: A General Signature of Adult Stem Cell Compartments. Genes \& Development, 22, 654-667. https://doi.org/10.1101/gad.451008

[37] Seluanov, A., Chen, Z., Hine, C., Sasahara, T., Ribeiro, A., Catania, K., Presgraves, D. and Gorbunova, V. (2007) Telomerase Activity Coevolves with Body Mass Not Lifespan. Aging Cell, 6, 45-52. https://doi.org/10.1111/j.1474-9726.2006.00262.x

[38] Kim, N.M., Piatyszek, M.A., Prowse, K.R., Harley, C.B., West, M.D., Ho, P.L.C., Coviello, G.M., Wright, W.E., Weinrich, S.L. and Shay, J.W. (1994) Specific Association of Human Telomerase Activity with Immortal Cells and Cancer. Science, 266, 2011-2015. https://doi.org/10.1126/science.7605428

[39] Yashima, K., Maitra, A., Rogers, B.B., Timmons, C.F., Rathi, A., Pinar, H., Wright, W.E., Shay, J.W. and Gazdar, A.F. (1998) Expression of the RNA Component of Telomerase during Human Development and Differentiation. Cell Growth \& Differentiation, 9, 805-813.

[40] Jorgensen, P.B., Fedder, J., Koelvraa, S. and Graakjaer, J. (2013) Age-Dependence of Relative Telomere Length Profiles during Spermatogenesis in Man. Maturitas, 75, 380-385. https://doi.org/10.1016/j.maturitas.2013.05.001

[41] Erdem, H.B., Bahsi, T. and Ergün, M.A. (2021) Function of Telomere in Aging and Age Related Diseases. Environmental Toxicology and Pharmacology, 85, Article ID: 103641. https://doi.org/10.1016/j.etap.2021.103641

[42] Egger, G., Liang, G., Aparicio, A. and Jones and P.A. (2004) Epigenetics in Human Disease and Prospects for Epigenetic Therapy. Nature, 429, 457-463. https://doi.org/10.1038/nature02625

[43] Baird, D.M. (2008) Telomeres II. Experimental Gerontology, 43, 15-19. https://doi.org/10.1016/j.exger.2007.10.002

[44] Wood, A.J. and Oakey, R.J. (2006) Genomic Imprinting in Mammals: Emerging Themes and Established Theories. PLoS Genetics, 2, Article No. e147. https://doi.org/10.1371/journal.pgen.0020147

[45] Asghar, M., Bensch, S., Tarka, M., Hansson, B. and Hasselquist D. (2015) Maternal and Genetic Factors Determine Early Life Telomere Length. Proceedings of the Royal Society B, 282, Article ID: 20142263. https://doi.org/10.1098/rspb.2014.2263

[46] Kin, A., Kansaku, K., Sumiya, M., Itami, N., Sirasuna, K., Kuwayama, T. and Iwata, H. (2017) Effect of Aging on Telomere Lengths in Bovine Oocytes and Granulosa Cells. Journal of Mammalian Ova Research, 34, 37-43.

[47] Gomes, N.M., Ryder, O.A., Houck, M.L., Charter, S.J., Walker, W., Forsyth, N.R., Austad, S.N., Venditti, C., Pagel, M., Shay, J.W. and Wright, W.E. (2011) Comparative Biology of Mammalian Telomeres: Hypotheses on Ancestral States and the Roles of Telomeres in Longevity Determination. Aging Cell, 10, 761-768. https://doi.org/10.1111/j.1474-9726.2011.00718.x

[48] Ozturk, S., Sozen, B. and Demir, N. (2013) Telomere Length and Telomerase Activity during Oocyte Maturation and Early Embryo Development in Mammalian Species. Molecular Human Reproduction, 20, 15-30. 
https://doi.org/10.1093/molehr/gat055

[49] Reizel, Y., Itzkovitz, S., Adar, R., Elbaz, J., Jinich, A., Chapal-Ilani, N., Maruvka, Y.E., Nevo, N., Marx, Z., Horovitz, I., Wasserstrom, A., Mayo, A., Shur, I., Benayahu, D., Skorecki, K., Segal, E., Dekel, N. and Shapiro, E. (2012) Cell Lineage Analysis of the Mammalian Female Germline. PLoS Genetics, 8, e1002477.

https://doi.org/10.1371/journal.pgen.1002477

[50] Fromer, M., Pocklington, A.J., Kavanagh, D.H., Williams, H.J., Dwyer, S., Gormley, P., Georgieva, L., Rees, E., Palta, P., Ruderfer, D.M., Carrera, N., Humphreys, I., Johnson, J.S., Roussos, P., Barker, D.D., Banks, E., Milanova, V., Grant, S.G., Hannon, E., Rose, S.A., Chambert, K., Mahajan, M., Scolnick, E. M., Moran, J.L., Kirov, G., Palotie, A., McCarroll, S.A., Holmans, P., Sklar, P., Owen, M.J., Purcell, S. M. and O’Donovan, M.C. (2014) De Novo Mutations in Schizophrenia Implicate Synaptic Networks. Nature, 506, 179-184. https://doi.org/10.1038/nature12929

[51] Krupp, G., Bonatz, G. and Parwaresch, R. (2000) Telomerase, Immortality and Cancer. Biotechnology Annual Review, 6, 103-140. https://doi.org/10.1016/S1387-2656(00)06020-8

[52] Sartorius, G.A. and Nieschlag, E. (2010) Paternal Age and Reproduction. Human Reproduction Update, 16, 65-79. https://doi.org/10.1093/molehr/gat021

[53] Turner, S. and Hartshorne, G.M. (2013) Telomere Lengths in Human Pronuclei, Oocytes and Spermatozoa. Molecular Human Reproduction, 19, 510-518. https://doi.org/10.1093/molehr/gat021

[54] Varela, E., Munoz-Lorente, M.A., Tejera, A.M., Ortega, S. and Blasco, M.A. (2016) Generation of Mice with Longer and Better Preserved Telomeres in the Absence of Genetic Manipulations. Nature Communications, 7, Article No. 11739.

https://doi.org/10.1038/ncomms11739

[55] Haycock, P.C., Heydon, E.E., Kaptoge, S., Butterworth, A.S., Thompson, A. and Willeit, P. (2014) Leucocyte Telomere Length and Risk of Cardiovascular Disease: Systematic Review and Meta-Analysis. BMJ, 349, Article No. g4227. https://doi.org/10.1136/bmj.g4227

[56] Aviv, A., Anderson, J.J. and Shay, J.W. (2017) Mutations, Cancer and the Telomere Length Paradox. Trends in Cancer, 3, 253-258. https://doi.org/10.1016/j.trecan.2017.02.005

[57] Sharma, R., Agarwal, A., Rohra, V.K., Assidi, M., Abu-Elmagd, M. and Turki, R.F. (2015) Effects of Increased Paternal Age on Sperm Quality, Reproductive Outcome and Associated Epigenetic Risks to Offspring. Reproductive Biology and Endocrinology, 13, Article No. 35. https://doi.org/10.1186/s12958-015-0028-X

[58] Stone, B.A., Alex, A., Werlin, L.B. and Marrs, R.P. (2013) Age Thresholds for Changes in Semen Parameters in Men. Fertility and Sterility, 100, 952-958. https://doi.org/10.1016/j.fertnstert.2013.05.046

[59] Ehrlenbach, S., Willeit, P., Kiechl, S., Willeit, J., Reindl, M., Schanda, K., Kronenberg, F. and Brandstätter, A. (2009) Influences on the Reduction of Relative Telomere Length over 10 Years in the Population-Based Bruneck Study: Introduction of a WellControlled High-Throughput Assay. International Journal of Epidemiology, 38, 1725-1734. https://doi.org/10.1093/ije/dyp273

[60] Fitzpatrick, A.L., Kronmal, R.A., Kimura, M., Gardner, J.P., Psaty, B.M., Jenny, N.S., Tracy, R.P., Hardikar, S. and Aviv, A. (2011) Leukocyte Telomere Length and Mortality in the Cardiovascular Health Study. Journal of Gerontology and Geriatrics: Series A, 66, 421-429. https://doi.org/10.1093/gerona/glq224

[61] Harley, C. (1991) Telomere Loss: Mitotic Clock or Genetic Time Bomb? Mutation Research/DNAging, 256, 271-282. https://doi.org/10.1016/0921-8734(91)90018-7 
[62] Aydos, S.E., Elhan, A.H. and Tükün, A. (2005) Is Telomere Length One of the Determinants of Productive Life Span? Archives of Gynecology and Obstetrics, 272, 113-116. https://doi.org/10.1007/s00404-004-0690-2

[63] Gray, K.E., Schiff, M.A., Fitzpatrick, A.L., Kimura, M., Aviv, A. and Starr, J.R. (2014) Leukocyte Telomere Length and Age at Menopause. Epidemiology, 25, 139-146. https://doi.org/10.1097/EDE.0000000000000017

[64] Shenassa, E.D. and Rossen, L.M. (2015) Telomere Length and Age-at-Menopause in the US. Maturitas, 82, 215-221. https://doi.org/10.1016/j.maturitas.2015.07.009

[65] Haycock, P.C., Burgess, S., Nounu, A., Zheng, J., Okoli, G.N., et al. (2017) Association between Telomere Length and Risk of Cancer and Non-Neoplastic Diseases: A Mendelian Randomization Study. JAMA Oncology, 3, 636-651.

https://doi.org/10.1001/jamaoncol.2016.5945

[66] Ma, H., Zhou, Z., Wei, S., Liu, Z., Pooley, K.A., Dunning, A.M., Svenson, U., Roos, G., Hosgood, H.D., Shen, M. and Wei, Q. (2011) Shortened Telomere Length Is Associated with Increased Risk of Cancer: A Meta-Analysis. PLoS ONE, 6, e20466. https://doi.org/10.1371/journal.pone.0020466

[67] Zhu, X., Han, W., Xue, W., Zou, Y., Xie, C., Du, J. and Jin, G. (2016) The Association between Telomere Length and Cancer Risk in Population Studies. Scientific Reports, 6, Article No. 22243. https://doi.org/10.1038/srep22243

[68] Rode, L., Nordestgaard, B.G. and Bojesen, S.E. (2016) Long Telomeres and Cancer Risk among 95,568 Individuals from the General Population. International Journal of Epidemiology, 45, 1634-1643. https://doi.org/10.1093/ije/dyw179 